\title{
Social accounting matrix and the effects of economic reform on health price index and household expenditures: Evidence from Iran
}

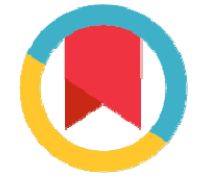

\author{
Khosro Keshavarz ${ }^{1}$, Behzad Najafi ${ }^{2}$, Yaghob Andayesh ${ }^{3}$, Aziz Rezapour ${ }^{4}$, Masoud Abolhallaj ${ }^{5}$, Ali Sarabi Asiabar ${ }^{4}$, Amir \\ Hashemi Meshkini ${ }^{6}$, Ehsan Sanati ${ }^{6}$, Iman Mirian $^{1}$, Shekoofeh Nikfar ${ }^{6}$, Farhad Lotfi ${ }^{1 *}$
}

Received: 28 Feb 2016

Published: 2 Oct 2017

\section{Abstract}

Background: Socioeconomic indicators are the main factors that affect health outcome. Health price index (HPI) and households living costs (HLC) are affected by economic reform. This study aimed at examining the effect of subsidy targeting plan (STP) on HPI and HLC.

Methods: The social accounting matrix was used to study the direct and indirect effects of STP. We chose 11 health related goods and services including insurance, compulsory social security services, hospital services, medical and dental services, other human health services, veterinary services, social services, environmental health services, laundry\& cleaning and dyeing services, cosmetic and physical health services, and pharmaceutical products in the social accounting matrix to examine the health price index. Data were analyzed by the I-O\&SAM software.

Results: Due to the subsidy release on energy, water, and bread prices, we found that (i) health related goods and services groups' price index rose between $33.43 \%$ and $77.3 \%$, (ii) the living cost index of urban households increased between $48.75 \%$ and $58.21 \%$, and (iii) the living cost index of rural households grew between $53.51 \%$ and $68.23 \%$. The results demonstrated that the elimination of subsidy would have negative effects on health subdivision and households' costs such that subsidy elimination increased the health prices index and the household living costs, especially among low-income families. The STP had considerable effects on health subdivision price index.

Conclusion: The elimination or reduction of energy carriers and basic commodities subsidies have changed health price and households living cost index. Therefore, the policymakers should consider controlling the price of health sectors, price fluctuations and shocks.

Keywords: Subsidy Targeting, Social Accounting Matrix, Price Index, Health Sector, Economic Reform, Iran

Copyright@ Iran University of Medical Sciences

Cite this article as: Keshavarz Kh, Najafi B, Andayesh Y, Rezapour A, Abolhallaj M, Sarabi Asiabar A, Hashemi Meshkini A, Sanati E, Mirian I, Nikfar Sh, Lotfi F. Social accounting matrix and the effects of economic reform on health price index and household expenditures: Evidence from Iran. Med J Islam Repub Iran. 2017 (2 Oct);31:68. https://doi.org/10.14196/mjiri.31.68.

\section{Introduction}

The subsidization of goods and services in all countries has many objectives such as supporting the low-income population and poor or consumption of some essential goods. In Iran's economy, subsidy programs were de-

\footnotetext{
Corresponding author: Dr Farhad Lotfi, lotfifarhad@gmail.com
}

1. Health Human Resources Research Center, Department of Health Economics, School of Management \& Medical Informatics, Shiraz University of Medical Sciences, Shiraz, Iran.

2. Iranian center of Excellence in health management, Department of health services management, School of management and medical informatics, Tabriz University of medical sciences, Tabriz, Iran.

3. Department of Economics, Shahid Chamran University of Ahvaz, Ahvaz, Iran.

${ }^{4}$. Health Management and Economics Research Center, Iran University of Medical Sciences, Tehran, Iran.

5. Assistant Professor in Health Services Management, Budgeting and performance Monitoring Center, Ministry of Health and Medical Education, Tehran, Iran.

6. Department of Pharmacoeconomics and Pharmaceutical Administration, Faculty of Pharmacy, Tehran University of Medical Sciences, Tehran, Iran. signed and performed to support the people, especially the 2 low- income quintiles during war and revolution. After the war, Iran's economy was stabilized, but the subsidies program continued without any changes (1). There are a

$\uparrow$ What is "already known" in this topic:

All goods and services price index are affected by economic reform. Among all goods and services, health related good can affect health services accessibility. However, no quantitative study has been conducted on the direct and indirect effects of subsidy target plan on health prices index in Iran.

\section{$\rightarrow$ What this article adds:}

We evaluated the effect of removing subsidy in energy carriers and basic commodities on health price and households living cost index. The elimination of subsidy had negative effects on health subdivision and households' costs. 
lot of subsidies paid for energy, water, foo ds, and drugs in Iran yearly (2). Therefore, a large amount of resource was allocated to subsidy, and the subject of targeted subsidy was brought up (1).

Enhancing oil revenue, increasing the consumptions due to population growth and expectation, and inadequate growth of domestic production led to high inflation in Iran's economy in the last 2 decades. The inflation control of some goods such as basic commodities led to a deep gap in prices of goods. The subsidies are one of the main economic problems that policymakers are face with in order to cover the gap (3).

To overcome this problem, many attempts were made by policymakers and researchers, one of which is the enacting of subsidy targeting plan (STP) by Iranian parliament, implemented on December 2010. Inflation is one of the main impacts of STP that led to the rise in prices of basic commodities, and consequently, the price of other products and services. Health sector is one of the main sectors affected by inflation, and the policymakers are concerned about the fluctuation of price of health services.

To date, no study has been conducted on the direct and indirect effects of STP on health prices index by applying quantitative economical models in Iran; however, there are 2 papers on drug subsidies which used social accounting matrix (SAM). The first study has been carried out in 2004, and the findings showed that when drug subsidies are eliminated, the low-income quintiles incur more losses compared to the high-income quintiles (4). The results of the second study revealed that the elimination of drug subsidies increases the price index of all sectors and also increases the living cost index of all of the households groups (5). There are several papers about the effects of subsidies reduction on different sectors, some of which reported positive effects, and others reported negative effects on more sectors. Mojtahed (1999) studied the effects of bread subsidies reduction on government costs. He found that subsidies elimination had negative effects on economy growth, the private sector consumption, and investment, import, employment, and income distribution (6). The study by Lofgreen and Al Saeed (2001) showed that targeted subsidies for 4 goods (sugar, bread, flour, and oil) led to an increase in the total society consumptions by $5 \%$ and in rural societies consumptions by $1 \%$ (7). Seshamani (1998) revealed that the corn subsidies removal in Zambia could not stimulate the production and led to insecurity in food (8). The study by Laraki (1989) in Egypt showed that because of the high price elasticity of vegetable oil in rural and urban areas, and sugar in urban areas, the increase in their price had negative nutritional effects (9).

Since the STP has been enacted in Iran (2010), several studies have been conducted to examine the impacts of targeted subsidies on inflation growth; however, its effects on health sector have not been studied yet. The present study aimed at examining the effect of STP on health price index and household expenditure. The results of this study could be used by health policymakers in Iran to evaluate the positive and negative effects of enforced policies.

\section{Methods}

This was an empirical study including all the economic sectors and households in Iran. We used the social accounting matrix (SAM) of Iran (2001). This matrix includes national accounts information about the whole economic sector obtained from the Iran Statistics Center Information.

Social accounting matrix is an appropriate method for analyzing the effects of energy carriers, water, and basic commodities subsidies elimination on health subdivisions' price index and households' living cost index; and it has 5 basic economic accounts as follows: (1) production, (2) production factor, (3) institutions, (4) investment, and (5) abroad (external) accounts. It enables us to analyze the socioeconomic impact of any reform simultaneously.

This matrix consists of 161 rows and columns in which 147 rows and columns are about goods in production account, 3 rows and columns about production factors, 1 row and 1 column about firms, and 10 columns and rows about rural and urban households quintiles.

We used cost approach in this research and analyzed the effects of energy carriers, water, and basic commodities subsidies reduction on health price index (HPI) and households living costs (HLC). We chose 11 health related goods and services groups in the social accounting matrix to examine health price index. For examining the effect of STP on household expenditure, we categorized the households in 2 categories and 10 quintiles. We shocked the matrix by changes in prices based on STP (Table 1) and measured the HPI and HLC, and analyzed the results by general multiplier the social accounting matrix. Data were analyzed using the I-O\&SAM software.

In general, there are 3 price indices in SAM:

The producer price index (PPI) is calculated as below:

$$
P_{1}=P_{1} B_{11}+P_{2} B_{21}+P_{4} B_{41} \quad \text { Equation (1) }
$$

where $P_{1} B_{11}$ represents the price of intermediate goods

\begin{tabular}{ccc}
\multicolumn{2}{c}{ Table 1. Goods' Price Increase during the First Phase of Subsidy Targeting Plan } \\
\hline No. & Goods and Production Fac- & Price Increase on Average (\%) \\
& tors & 540 \\
\hline $\mathbf{1}$ & Bread & 600 \\
$\mathbf{2}$ & Gasoline & 506 \\
$\mathbf{3}$ & Petroleum & 2021 \\
$\mathbf{4}$ & Diesel & 2016 \\
$\mathbf{5}$ & Fuel oil & 9608 \\
$\mathbf{6}$ & LPG & 341 \\
$\mathbf{7}$ & Natural gas & 118 \\
$\mathbf{8}$ & Electricity & 108 \\
$\mathbf{9}$ & Water & \\
\hline
\end{tabular}


multiplied by the weight of products value, $P_{2} B_{21}$ production price multiplied by production share and $P_{4} B_{41}$ exogenous cost of production.

Production factor price index:

$$
P_{2}=P_{3} B_{32}+P_{4} B_{42} \quad \text { Equation (2) }
$$

$\mathrm{P}_{2}$ is the production factor price index, $\mathrm{P}_{3} \mathrm{~B}_{32}$ represents living cost index multiplied by allocation matrix, and $\mathrm{P}_{4} \mathrm{~B}_{42}$ represents the exogenous factor price multiplied by their share of utilization in production.

Household living cost index is calculated as follows:

$$
P_{3}=P_{1} B_{13}+P_{3} B_{33}+P_{4} B_{43} \quad \text { Equation (3) }
$$

where $P_{3}$ shows the cost of living index, $P_{1} B_{13}$ represents price of purchase products multiplied by their share of household consumption basket, $P_{3} B_{33}$ is the values of transitions between organizations and $P_{4} B_{43}$ is exogenous factor price.

It can be concluded that the prices in SAM are related to one another and to the exogenous variables from Equation 1. In addition, measurement of price in different parts of all sectors should be examined simultaneously. The equations can be briefly indicated in matrix form as bellow:

$$
\begin{array}{ll}
P=P B n+L & \text { Equation (4) } \\
P-P B n=L & \text { Equation (5) } \\
P(I-B n)=L & \text { Equation (6) } \\
\mathrm{P}=\mathrm{L}(\mathrm{I}-\mathrm{Bn})^{-1} & \text { Equation (7) } \\
\mathrm{P}=\mathrm{L} . \mathrm{M} & \text { Equation (8) } \\
\Delta P=\Delta L . M & \text { Equation (9) }
\end{array}
$$

If we use the transpose of $B$ instead of $B$, it is shown as below:

$$
\begin{aligned}
& P=M^{\prime} . L \\
& \Delta P=M^{\prime} \Delta L
\end{aligned}
$$$$
\text { Equation (10) }
$$

where $\mathrm{M}$ is the common incremental coefficient matrix of the social accounting matrix, $M^{\prime}$ is incremental coefficient cost and $\mathrm{L}$ is exogenous world of the social accounting matrix.

$\mathrm{M}^{-}$equal to $\left(I-B_{n}^{\prime}\right)^{-1}$ and $\mathrm{L}$ is the exogenous sector in
SAM. To obtain a detailed analysis, we divided $\mathrm{M}^{-}$in 3 matrices:

$$
M^{\prime}=\left(I-B^{3^{*}}\right)^{-1}\left(I+B^{*}+B^{2^{*}}\right)(I-\bar{B})^{-1}=M_{1}^{\prime} M_{2}^{\prime} M_{3}^{\prime}
$$

$\mathrm{M}_{1}^{-}, \mathrm{M}_{2}$ and $\mathrm{M}_{3}^{-}$are the transpose of $\mathrm{M}_{1}, \mathrm{M}_{2}$, and $\mathrm{M}_{3}$. $M_{1}$ is the vector of direct and indirect impact of intermediate transactions intrasectors. It is Leontief multipliers or closed loop multipliers in production account.

$\mathrm{M}_{2}$ is known as opened loop multipliers matrix. It means that when we change the price of an input, it affects the account, but it is followed by another account. It is not spin. $\mathrm{M}_{3}$ is a known closed loop multiplier as well. In $\mathrm{M}_{3}$ when we change the price, it affects the one account directly and indirectly, and then this effect, affect another account. Then, these changes affect the first account again. In fact, $\mathrm{M}_{3}$ explains the direct and indirect effects of the production process.

In this study, we changed the price of energy carrier, water, and bread according to Table 2. Then, we followed their effects on health related goods and services groups and household living costs.

\section{Results}

The results of this study were reported in 2 parts. In the first part, we appraised the effects of energy carriers, water, and basic commodities subsidies elimination on health related goods and services' price index; and in the second part, we explained its impacts on rural and urban households living cost index.

Based on the first phase of implementation of STP, the

\begin{tabular}{|c|c|c|c|c|}
\hline \multirow[b]{2}{*}{ Sector No. } & \multirow[b]{2}{*}{ Subdivision } & \multicolumn{3}{|c|}{ Effects of the First phase of STP } \\
\hline & & Bread & Energy and Water & Subtotal \\
\hline 108 & Insurance & 5.292 & 28.2 & 33.49 \\
\hline 126 & Compulsory social security services & 4.428 & 29 & 33.43 \\
\hline 134 & Hospital services & 6.426 & 41.7 & 48.13 \\
\hline 135 & Medical and dental services & 5.832 & 36 & 41.83 \\
\hline 136 & Other human health services & 6.048 & 54.2 & 60.25 \\
\hline 137 & Veterinary services & 5.67 & 37.8 & 43.47 \\
\hline 138 & Social services & 7.02 & 53.3 & 60.32 \\
\hline 139 & Environmental health services (sewage disposal, etc.) & 5.508 & 63.3 & 68.81 \\
\hline 145 & Laundry, cleaning, and dyeing services & 5.67 & 56.6 & 62.27 \\
\hline 146 & cosmetic and physical health services & 5.67 & 57.1 & 62.77 \\
\hline 56 & Pharmaceutical products & 2.8 & 74.5 & 77.3 \\
\hline
\end{tabular}
price of energy, water, and bread was increased according to Table 1. The effects of the first phase of STP in Iran (2010) are as follow: The price of oil, sugar, edible oil (vegetable oil), and drug has not changed. It should be noted that flour price rising was not considered to avoid double accounting its effect because it is an intermediate good for cooking bread.

We imported these changes in the model and followed their effects in sectors. According to the first phase of implementing STP, with increasing the prices of bread, energy carriers, and water, the health related goods and services' price index increased from 33.43 to 77.3 . These effects are presented in Table 2 separately.

According to Table 2, the pharmaceutical products, environmental health services, and cosmetic and physical

Table 2. The Effects of Implementing the First Phase of STP on the Health Related Goods and Services' Price Index 
Table 3. The Effects of Implementing the First Phase of STP on the Living Costs of Urban and Rural Household Quintiles

\begin{tabular}{|c|c|c|c|c|c|}
\hline \multirow{3}{*}{$\begin{array}{c}\text { Sector No. } \\
108\end{array}$} & \multirow{2}{*}{\multicolumn{2}{|c|}{$\begin{array}{l}\text { Household Group (quintile) } \\
\left(\mathrm{U}_{1} \text { and } \mathrm{r}_{1} \text { are the poorest and } \mathrm{u}_{5} \text { and } \mathrm{r}_{5} \text { are the richest) }\right.\end{array}$}} & \multicolumn{3}{|c|}{ Effects of the First Phase of STP } \\
\hline & & & Bread & Energy and Water & Subtotal \\
\hline & Urban & $\mathrm{U}_{1}$ & 15.71 & 42.5 & 58.21 \\
\hline 126 & & $\mathrm{U}_{2}$ & 11.83 & 44.1 & 55.93 \\
\hline 134 & & $\mathrm{U}_{3}$ & 10.37 & 43.1 & 53.47 \\
\hline 135 & & $\mathrm{U}_{4}$ & 8.80 & 44.3 & 53.1 \\
\hline 136 & & $\mathrm{U}_{5}$ & 6.05 & 42.7 & 48.75 \\
\hline 137 & Rural & $\mathrm{R}_{1}$ & 16.63 & 51.6 & 68.23 \\
\hline 138 & & $\mathrm{R}_{2}$ & 14.58 & 52.0 & 66.58 \\
\hline 139 & & $\mathrm{R}_{3}$ & 12.53 & 50.1 & 62.63 \\
\hline 145 & & $\mathrm{R}_{4}$ & 10.91 & 50.5 & 61.41 \\
\hline 146 & & $\mathrm{R}_{5}$ & 7.61 & 45.9 & 53.51 \\
\hline
\end{tabular}

health were affected more than other health sectors (77.3\%, 62.77\%, and $62.27 \%$ respectively).

The social security, insurance services, and medical and dental services were affected less than the others $(33.43 \%$, $33.49 \%$ and $41.83 \%$ respectively).

In addition, the other health related goods and services' price index has been increased considerably by removing the subsidy from bread, water, and energy prices (eg, social service: $60.32 \%$; other human health services: $60.25 \%$; and hospital services: $48.13 \%$ ). The compulsory social security services had the lowest growth in its price index $(33.43 \%)$, and pharmaceutical products had the highest increase in price index $(77.3 \%)$. Because the pharmaceutical products subsidies were not removed in the first stage (phase) of implementing STP, their effects were not determined.

To estimate the impact of subsidy targeting on household expenditure, we categorized them in 2 groups: Rural and urban households. Afterwards, we categorized both of them in 5 groups by average annual income (quintile). The effect of STP on household expenditure is presented in Table 3 .

The price of bread and energy carriers increased due to implementation of STP, affecting the living cost index of urban and rural households. Urban household expenditure grew from $48.75 \%$ to $58.21 \%$, while rural household expenditure grew from $53.51 \%$ to $68.23 \%$.

Removal of bread subsidy affected the quintile 1 more in both rural and urban households rather than the others. Moreover, the removal of energy subsidy affected the quintile 4 in the urban and quintile 2 in the rural household more than the others.

\section{Discussion}

The effects of basic commodities and energy subsidies elimination were determined on health sector price index and households living cost index by the social accounting matrix. In general, during the first phase of the implementation of the STP, the price index increased from 33\% to $68 \%$ in the subdivision of the health sector. Hospital services price increased to $48.13 \%$. This categorization is different from NHA categories. Nevertheless, if we suppose the hospital and curative services are similar, we can estimate that the curative service expenditure would increase due to implementation of STP. Based on NHA (2011), 61\% of Iranian health expenditure has been spent in curative services (10). Therefore, $61 \%$ of the total health expenditure could increase by $48.13 \%$ due to STP.
It means that the policy makers should manage the financial resource and health expenditure effectively. Because the out- of- packet expenses will rise if public financing does not increase in health care.

Overall, the first phase of the STP influences the health sector price index considerably. Moreover, in the first phase of the STP, the urban households living cost index increased from $48.75 \%$ to $58.21 \%$, while the living cost index of rural household increased from $53.51 \%$ to $68.23 \%$, meaning that if the subsidies of bread and energy carriers are eliminated, the rural households incur more losses than the urban households. The low-income households are affected more than the high-income ones both in the rural and urban areas. As demonstrated in Table 3, the trend of living cost index in the rural and urban household quintile was the same. It decreased when we moved to Quintile 5 from Quintile 1 in both categories. Moreover, the living cost index variation was vast in the rural household compared to the urban.

Because the rich households consume energy more than the poor, we expect that STP (especially energy subsidy removal) would affect the urban household expenditure more than the rural household. However, the results showed that the impact of STP on the poor household was more than the rich ones. This can be due to the high expenditure in the rich households rather than the poor, so the share of energy in rich households is less than the poor.

It is expected that subsidies and transfer payments lead to decreasing poverty in the short- or long- run (11), moreover, in a short time the energy, bread, and water price liberalization increases the household expenditure and leads to reduction in consumers' purchasing power. While the economic text mentioned that economic liberalization can lead to high social welfare (12), it is not our goal, and we do not estimate the social welfare. On the other hand, based on the STP, the portion of subsidy must be paid to people in cash by the government $(13,14)$. It can be apprised what changes have occurred in the social welfare with the increase in the living cost index and gain from STP.

Some studies confirm these conclusions. Andayesh, et al. (2005), for example, found that if the subsidies decrease in the agriculture sector, the price index will be increased in all economic sectors and that the rural households' living cost index increased more than the urban households (15). A study by Andayesh (2010) concluded that the elimination of drugs subsidies increases the price index of all sectors and also increases all the household 
groups living cost index (5). On the other hand, some of these results are not consistent with some other studies. Sharifi, et al. (2008), for example, concluded that the increase in the price of energy carriers affected all sectors similarly (16).

Our findings on the effect of STP on household expenditure confirm the results of Banooi's study (2004) that showed the low-income households incur more losses than the high-income households(17), with the implementation of this program. Moreover, our finding is in agreement with that of the Gupta's study that demonstrated the subsidies elimination might have reverse effects on the poor households, so its effects should reduce or be compensated (18).

\section{Conclusion}

According to the results of our study, it can be concluded that the elimination or reduction of energy carriers and basic commodities subsidies changed health price and households living cost index. In addition, it increased the living cost of the low-income households' more than the high-income ones. Overall, during the first phase of the STP implementation, an increase was observed in the price index of the health sector (from $33 \%$ to $77 \%$ ). Indeed, it can be mentioned that the first stage of this program had considerable impact on health sector price index.

Thus, it is suggested that to avoid the comprehensive effects of subsidies elimination of energy and basic commodities, policymakers should control the price of the health sectors, price fluctuations, and shocks. So considering the implementation of the STP and the increase in health related goods and services, price index, and households living cost index, the policies should be made to reduce the pressure on the households and facilitate the continuance of STP. Below, there are some recommendations and key massages for the policymakers:

- Health is one of the sectors that has low priority in households' consumption basket. Thus, with increasing inflation and living cost index due to implementation of STP, it is expected that this sector go down again for consumption priority. Therefore, to maintain the high priority of the health services consumption, the government should control price inflation and provide finance to the public sector.

- The Fifth Program of Socioeconomic and Culture Development of Iran stated that out- of- pocket expenses should be reduced to $30 \%$. Moreover, if the government does not control the price index in the health sector and does not change the health financing methods, it would not only be impossible to achieve this goal but also it could be increased due to effect of STP.

- In subsidy allocation, heath sectors should have a high priority.

- More subsidies should be allocated to services that have lower price elasticity and more health effects. It is important that if the governments cannot establish equity, they should reduce health services prices to protect poor individuals with the best policy and method.
- More subsidies should be allocated to areas where the private sector is limited (eg, allocating more subsidies to rural areas).

- The country's health infrastructure and a comprehensive system for social security should be developed and improved.

\section{Acknowledgments}

This study was funded and supported by Tehran University of Medical Sciences (TUMS) (Grant no: 9002-6413882. TUMS).

\section{Conflict of Interests}

The authors declare that they have no competing interests.

\section{References}

1. Ghahramani Saghir H. How to prevent the drug wasting. The first congress of prevention from wasting national resources; Tehran: Academy of sciences of Islamic Republic of Iran; 2004: 171-9 [Persian]

2. Ebadi J, Ghavam MH. Allocation of Pharma Subsidies with Respect to Efficiency and Equality. Eco Res. 2009;44(1):131-162. [Persian]

3. Feizi E. Drug's Subside, Iranian Parliament's Research Center, 2006 [Persian]

4. Ministry of health. Reducing the consequences of drug subsidies on household deciles. [project manager institute of religion and the economy]. Tehran: Ministry of Health; 2004. [Persian]

5. Andayesh Y, Keshavarz K, Zahiri M, Mirian I, Beheshti A, Imani A, et al. The effects of drug subsidies exclusion on price index of sectors and households expenditures; using structural path analysis. J Health Administ. 2011;13(42):45-56.

6. Mojtahed A. Effects of pay and reduction of subsidies on bread in the economy. Economics of wheat production to consumption, Collection of research papers. Tehran: Institute for Planning and Agricultural Economics; 1999. [Persian]

7. Löfgren H, El-Said M. Food subsidies in Egypt: reform options, distribution and welfare. Food Pol, 2001;26(1):65-83.

8. Seshamani V. The impact of market liberalisation on food security in Zambia. Food Pol. 1998; 23(6):539-51.

9. Laraki K. Food subsidies: A case study of price reform in Morocco, World Bank; 1989.

10. Statistical Center of Iran. National Health Accounts 2002-2008. Tehran: 2011. [Persian]

11. Mahmood Z. Pakistan: The Impact of Economic Liberalisation on Poverty. Islamabad: Sustainable Development Policy Institute; 1999.

12. Kirby P. The social impact of economic liberalization: evidence from Latin America. Trocaire Dev Rev. 2000:49-80.

13. Doshmangir L, Doshmangir P, Abolhassani N, Moshiri E, Jafari M. Effects of Targeted Subsidies Policy on Health Behavior in Iranian Households: A Qualitative Study. Iran J Pub Health. 2015 Apr;44(4):570-9.

14. Zandian H, Olyaeemanesh A, Takian A, Hosseini M. Contribution of Targeted Subsidies Law to the Equity in Healthcare Financing in Iran: Exploring the Challenges of Policy Process. Electronic Phys. 2016 Feb;8(2):1892.

15. Andayesh Y. The effects of decrease in agriculture sector subsidies on price indices of sectors and households expenditures by using input-output approach. Tehran: Allame Tabatabai University, MSc Dissertation, 2005. [Persian]

16. Sharifi A, Sadeghi M, Ghasemi A. The evaluation of inflation effects caused by energy carrier subsidies omission. Econ Bull. 2008; 31: 91119. [Persian]

17. Banouei AA, Asgari M. Multiplier Analysis in the Framework of Many Producers and Many Consumers of the SAM for the Iranian Economy. Q Iran Econ Res. 2003; 14:39-56

18. Gupta S. Equity and efficiency in the reform of price subsidies: a guide for policymakers: International Monetary Fund; 2000. 